\title{
I solation and identification of Staphylococcus aureus from milk and milk products and their drug resistance patterns in Anand, Gujarat
}

\author{
H. C. Thaker, M. N. Brahmbhatt, J. B. Nayak
}

Department of Veterinary Public Health,

Veterinary College, Anand Agricultural University, Anand 388001, Gujarat, India

Corresponding author: Harsh C. Thaker, email: harshthaker2005@yahoo.co.in

Received: 30-04-2012, Accepted: 26-06-2012, Published Online: 05-11-2012

\begin{abstract}
How to cite this article:
Thaker HC, Brahmbhatt MN and Nayak JB (2013) I solation and identification of Staphylococcus aureus from milk and milk products and their drug resistance patterns in Anand, Gujarat, Vet World 6(1): 10-13. doi: 10.5455/vetworld.2013.10-13
\end{abstract}

\begin{abstract}
Aim: The study was carried out with aim to isolate Staphylococcus aureus from milk and milk products (pedha and curd) and determine antibiogram pattern of $S$. aureus isolates.

Materials and Methods: During 9 months duration of study a total of 160 milk and milk product samples (pedha and curd) were collected from different places in and around Anand city such as milk collection centre of Co-operative milk dairies, cattle farms, individual household, milk vendors and sweet shops. The samples were collected under aseptic precautions and were enriched in Peptone Water (PW) followed by direct plating on selective media viz. Baird-Parker Agar. The presumptive $S$. aureus isolates were identified by biochemical tests. Antibiogram pattern of $S$. aureus to antimicrobial agents were evaluated by disk diffusion method.

Results: Analysis of result revealed that out of total 160 samples of milk (100) and milk products i.e. curd (30) and pedha (30) resulted in the isolation of 10 isolates $(6.25 \%)$ of $S$. aureus. In the present study $S$. aureus isolates were found variably resistant to the antibiotics tested. The $S$. aureus isolates showed highest sensitivity towards cephalothin (100.00\%), co-trimoxazole $(100.00 \%)$, cephalexin $(100.00 \%)$ and methicillin $(100.00 \%)$ followed by gentamicin $(90.00 \%)$, ciprofloxacin $(80.00 \%)$, oxacillin $(70.00 \%)$, streptomycin $(60.00 \%)$ and ampicillin $(60.00 \%)$. The pattern clearly indicated that the overall high percent of $S$. aureus isolates were resistant to Penicillin-G (100.00\%) followed by ampicillin (40.00\%), oxytetracycline and oxacillin $(20.00 \%)$ and streptomycin and gentamicin $(10.00 \%)$
\end{abstract}

Conclusions: Results clearly suggested a possibility of potential public health threat of S. aureus resulting from contamination of milk and milk products with pathogenic bacteria is mainly due to unhygienic processing, handling and unhygienic environment.

Key words: antibiogram pattern, milk products, S. aureus, staphylococcal food poisoning

\section{I ntroduction}

Food-borne diseases (FBD) are defined by the World Health Organization as diseases of infectious or toxic nature caused by, or thought to be caused by the consumption of food or water. The pathogenesis of bacteria causing food-borne poisoning depends on their capacity to produce toxins after ingestion (in the digestive tract) or intoxication (ingestion of preformed toxins in foodstuff). Among the bacteria predominantly involved in these diseases, Staphylococcus aureus is a leading cause of gastroenteritis resulting from the consumption of contaminated food. Staphylococcal food poisoning is due to the absorption of Staphylococcal enterotoxins preformed in the food [1].

Milk and milk products are the prime habitat to complex microbial ecosystems; these are responsible for the broad variations in taste, aroma and texture of milk and milk products. Contamination of milk and milk products with pathogenic bacteria is mainly due to processing, handling and unhygienic environment. The occurrence of these pathogenic bacteria in milk and milk products can cause severe health hazards to people as they are highly susceptible to variety of microorganism because of high nutritive value and complex chemical composition [2].

Many contaminants find their way to raw milk, from which they gain access to dairy products $[3,4]$. Chapaval [5] found production of staphylococcal enterotoxins in milk when milk was stored at temperatures of $37^{\circ} \mathrm{C}$ to $42^{\circ} \mathrm{C}$ or when exposed to variations in temperature.

Staphylococcal food poisoning include symptoms such as sudden onset of nausea, vomiting, abdominal cramps and diarrhea [6].

On heating at normal cooking temperature, the bacteria may be killed but the toxins remains active [7]. Staphylococcal enterotoxins are highly heat resistant and are thought to be more heat resistant in foodstuffs than in a laboratory culture medium [8].

Besides these, enterotoxins producing $S$. aureus are most dangerous and harmful for the human health. About $50 \%$ strain of this organism are able to produce enterotoxins associated with food poisoning [9]. Illness 
Table-1. Morphological and culture characteristics of S. aureus

\begin{tabular}{lll}
\hline Isolated bacteria & Gram staining & Culture characteristics on selective media \\
\hline Staphylococcus aureus & Gram positive cocci (in clusters) & B PA: Typical jet black colonies surrounded by halo zone \\
\hline
\end{tabular}

Table-2. Biochemical characterisation of S. aureus.

\begin{tabular}{ll}
\hline Biochemical test & Reaction \\
\hline Catalase & Positive \\
Coagulase & Positive \\
DNase & Positive \\
Acetoin production & Positive \\
Oxidase & Negative \\
D-mannitol fermentation & Positive \\
\hline
\end{tabular}

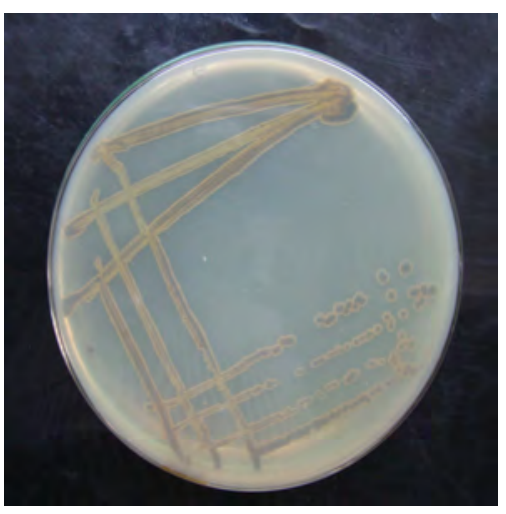

Figure-1. Colonies of $\mathrm{S}$. aureus on BairdParker agar showing typical jet black colonies surrounded by halo zone.

through $S$. aureus range from minor skin infection such as pimples, boils, cellulites, toxic shock syndrome, impetigo, and abscesses to life threatening disease such as pneumonia, meningitis, endocarditis, and septicaemia [2]. Especially in India, rate of infection is still higher because of warm and humid climate [10]. For many years, $S$. aureus was the only staphylococcal species known to produce enterotoxins [11].

Thus, the objective of this study was to investigate the occurrence of $S$. aureus in milk and milk products (pedha and curd) and determine antibiogram pattern of S. aureus isolates.

\section{Materials and Methods}

Sample collection: From February 2011 to October 2011, a total of 160 milk and milk product samples which includes raw milk (100 samples), curd (30 samples) and pedha (30 samples) were collected from different places in and around Anand city such as milk collection centres of Co-operative milk dairies, cattle farms, individual household, milk vendors and sweet shops. The samples were collected in sterilized milk collecting tubes and polyethylene bags and transported in an icebox to laboratory of the Post Graduate Department of Veterinary Public Health, College of Veterinary Science \& Animal Husbandry, AAU, Anand for further processing and microbiological analysis.

\section{I solation and I dentification of Staphylococcus aureus:}

Isolation of $S$. aureus was attempted according to Singh and Prakash [12] with slightmodification. Enrichment was carried out in Peptone Water (PW) enrichment broth (HiMedia Pvt. Ltd.). $10 \mathrm{ml}$ or $10 \mathrm{~g}$ sample was homogenized with $90 \mathrm{ml}$ sterile enrichment broth peptone water and enriched for $24 \mathrm{hrs}$ at $37^{\circ} \mathrm{C}$.

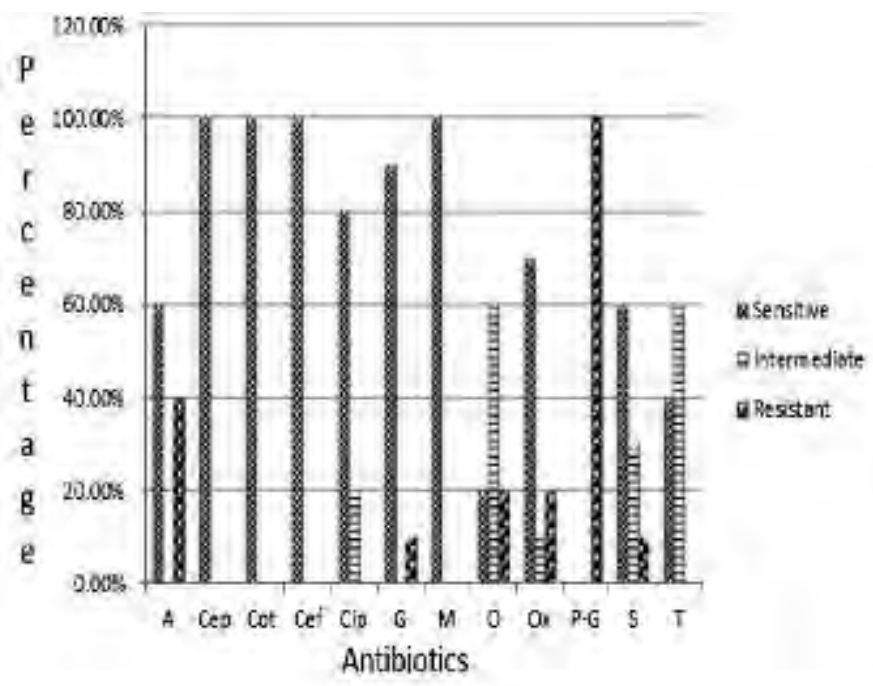

Figure-2. Antibiogram of S. aureus isolates

The selective medium used for isolation of $S$. aureus was Baird Parker Agar (BPA) (HiMedia Pvt. Ltd.). A loopful of inoculum from enrichment were streaked on BPagar and incubated for 48 hours at $37^{\circ} \mathrm{C}$. Characteristic appearance of jet black colonies surrounded by a white halo were considered to be presumptive $S$. aureus (Fig-1). The pure cultures were streaked on Nutrient agar (HiMedia Pvt. Ltd.) and incubated for 24 hours at $37^{\circ} \mathrm{C}$ and were further characterized by biochemical tests.

Morphological characteristics: The smear was prepared from the isolated culture on clean grease free microscopic glass slide and stained with Gram's method of staining. The stained smear was observed under microscope. Smear revealed Gram positive, spherical cells arranged in irregular clusters resembling to bunch of grapes.

Biochemical examination: Biochemical tests were performed to confirm $S$. aureus using Catalase test, Coagulase test, DNase test, Acetoin production, Oxidase test and D-mannitol fermentation.

Antibiogram pattern of the isolated S. aureus to some antimicrobial agents: The susceptibility of isolates to different anti-microbial agents was done by disk diffusion method using commercial disks [13] procured from HiMedia Pvt. Ltd. and almost all antimicrobial agents were having expiry date after 5-6 months of completion of research.

The antimicrobial agents tested were the following: ampicillin $(10 \mu \mathrm{g})$, cephalothin $(30 \mu \mathrm{g})$, co-trimoxazole $(1.25 / 23.75 \mu \mathrm{g})$, cephalexine $(30 \mu \mathrm{g})$,ciprofloxacin $(5 \mu \mathrm{g})$, gentamicin $(10 \mu \mathrm{g})$, methicillin $(5 \mu \mathrm{g})$, oxy-tetracycline $(30 \mu \mathrm{g})$, oxacillin $(1 \mu \mathrm{g})$, penicillin-G (10units), streptomycin $(10 \mu \mathrm{g})$ and tetracycline $(30 \mu \mathrm{g})$. 


\section{Results}

Analysis of result showed that out of total 160 samples of milk (100) and milk products i.e. curd (30) and pedha (30) resulted in the isolation of 10 isolates $(6.25 \%)$ of $S$. aureus.

Of the 100 milk samples, 30 pedha and 30 curd samples, $6(6.00 \%), 3(10.00 \%)$ and $1(3.33 \%)$ respectively were found to be positive for $\mathrm{S}$. aureus according to morphological and cultural characteristics (Table-1) and biochemical tests (Table-2).

In the present study, $S$. aureus isolates were found variably resistant to the antibiotics tested. The $S$. aureus isolates showed highest sensitivity towards cephalothin $(100 \%)$, co-trimoxazole $(100 \%)$, cephalexin $(100 \%)$ and methicillin (100\%) followed by gentamicin $(90 \%)$, ciprofloxacin $(80 \%)$, oxacillin $(70.00 \%)$, streptomycin $(60 \%)$ and ampicillin (60\%). The pattern clearly indicated that the overall high percent of $S$. aureus isolates were resistant to Penicillin-G (100\%) followed by ampicillin (40\%), oxytetracycline and oxacillin (20\%) and streptomycin and gentamicin (10\%).

Also intermediate sensitivity of $S$. aureus isolates was highest towards oxytetracycline and tetracycline $(60 \%)$, followed by streptomycin $(30 \%)$, ciprofloxacin (20\%) and oxacillin (10\%) (Fig. 2).

\section{Discussion}

Milk is normally sterile in the udder of the cow and buffalo provided they do not suffer from mastitis (udder infection). If they have mastitis, a large number of generally Gram positive bacteria such as Streptococcus and Staphylococcus spp. may be present in milk when it leaves the udder [14].

Negligence of hygienic condition such as improper cleaning of bulk tank, dirty udder, milking equipments, milk handling technique and improper storage will increase the proportion of Gram-positive and Gramnegative bacteria in the bulk tank milk $[15,16]$.

Food products serve not only as a source of nutrition but also as substrates for the growth of microorganisms. The growth of microorganisms causes food spoilage. It may result in food-borne illness. In tropical countries raw milk and milk products are responsible for many outbreaks of gastrointestinal tract. It is also reported that immunocompromised individuals are prone to food-borne infection [17].

Of the 100 milk samples, 30 pedha and 30 curd samples, $6(6 \%), 3(10 \%)$ and $1(3.33 \%)$ respectively were found to be positive for $S$. aureus. The highest incidence of S. aureus was from pedha (10\%), followed by milk samples $(6 \%)$ and curd $(3.33 \%)$.

The present overall isolation rate in milk and milk products was $6.25 \%$ which seems to be similar to the findings of $7.3 \%$ by Fagundes [18], 8.3\% by Shah [19] and $6.6 \%$ by Kumar and Prasad [20]. As compared to present findings higher level of incidence of $S$. aureus have been reported by Tambekar and Bhutda [21], Ekici [22], Santana [23], Zakary [24] and Lingathurai [25] who found $17.39 \%, 18.18 \%, 18.80 \%, 40 \%$ and

\section{$61.70 \%$ incidence respectively.}

The findings of present study are in accordance with the findings 8.3\% Shah [19], 9.50\% Ekici [22], $12.80 \%$ Normanno [26], $10.34 \%$ Singh and Prakash [12], 6.6\% Kumar and Prasad [20] and 10\% Addis [27].

The incidence of $S$. aureus in curd in the present study was $3.33 \%$. While lower incidence $0 \%$ was reported by Singh and Prakash [12] and higher incidence $6.66 \%$ was reported by Kumar and Prasad [20].

The incidence of $S$. aureus in pedha in the present study was $10.00 \%$ seems to be correlated with findings reported by Tambekar and Bhutda [21] 17.39\%. While higher incidence of $20 \%$ was reported by Kumar and Prasad [20].

The difference in the prevalence rates of $S$. aureus between milk and milk products may origin from the method of manufacture, storage and handling.

This study presents the sensitivity of the $S$. aureus isolates towards life saving drugs, viz., cephalothin, cephalexin and co-trimoxazole followed by gentamicin and ciprofloxacin thus indicating the safety of food products. However, few numbers of isolates exhibited resistance towards ampicillin, oxytetracycline and oxacillin.

Antibiotic resistance development among the bacteria poses a problem of concern. Effectiveness of current treatments and ability to control infectious diseases in both animals and humans may become hazardous.

\section{Conclusion}

Staphylococcal food poisoning is of major concern in public health programs worldwide. S. aureus may be present in milk and milk products as a result of milk collected from the animal suffering from disease condition and excreting $S$. aureus in milk or due to unhygienic conditions during production, processing, storage and handling of milk products, which are the main causes of food borne diseases. Results clearly indicated that milk and milk based products available in the market were contaminated with $S$. aureus, posing a high risk of food poisoning. Thus more hygienic preventive measures are required to reduce the bacterial contamination, so as to increase the wholesomeness of these milk and milk based products.

The indiscriminate use of antibiotics/antimicrobials agents for prophylactic as well as other therapeutic purpose could be the reasons for increased antimicrobial resistance of $S$. aureus. A relatively high number of strains are also resistant to the antibiotics commonly used in the therapeutic protocols of many human and animal infections. This study highlights the need for continuous surveillance of antibiotic sensitivity pattern of Staphylococcus aureus with a view to selecting appropriate therapy.

\section{Authors' contributions}

All authors contributed equally in the collection, analysis and processing of samples as well as preparation of 
manuscript for publication. All authors read and approved the final manuscript.

\section{Acknowledgements}

Authors are grateful to the Department of Veterinary Public Health, Anand Agricultural University, Anand for providing financial support to the present investigation.

\section{Competing interests}

The authors declare that they have no competing interests.

\section{References}

1. Loir, Y.L., Baron, F. and Gautier, M. (2003). Staphylococcus aureus and food poisoning. Gen. \& Mol. Res., 2(1): 63-76.

2. Soomro, A.H., Arain, M.A., Khaskheli, M. and Bhutto, B. (2003). Isolation of Staphylococcus aureus from milk products sold at sweet meat shops of Hyderabad. Online $J$. Biol. Sci., 3(1): 91-94.

3. Al-khatib, I.A. and Al-Mitwalli, S.M. (2009). Microbiological quality and sample collection policy for dairy products in Ramallah and Al-Bireh district, Palestine. East Mediterranean Heal. J., 15: 709-716.

4. Ismael, Z.S., Hosny, W.I., El-Kholy, W.I. and El-Dairouty, R.K. (2009). Comparative investigations for detection of foodborne microorganisms in Egyptian hard cheese (Ras): using conventional and fast biochemical test. J. Global Vet., 3: 189-195.

5. Chapaval, L., Moon, D.H., Gomes, J.E., Duarte, F.R. and Tsai, S.M. (2010). Efeito da temperatura sobre a produção de enterotoxina estafilocócica em leite. Revista Higiene Alimentar, 24: 180-181.

6. Balaban, N. and Rasooly, A. (2000). Staphylococcal enterotoxins. Int. J. Food Microbiol., 61: 1-10.

7. Presscott, L.M., Harley, J.P. and Klein, D.A. (2002). Text book of Microbiology. Brown Publishers. 5th ed.: 441-442.

8. Bergdoll, M.S. (1983). Enterotoxins. Staphylococci and Staphylococcal Infections (Easman, C.S.F. and Adlam, C., eds.). Academic Press, London, UK.: 559-598.

9. Payne, D.N. and Wood, J.M. (1974). The incidence of enterotoxin production in strains of Staphylococcus aureus isolated from food. J. Appl. Bacteriol., 37(3):319-325.

10. Bhatia, A. and Zahoor, S. (2007). Staphylococcus aureus Enterotoxins: A Review. J. Clin. \& Diag. Res., 1: 188-197.

11. Haluk, C., Leyla, V. and Nebahat, B.O. (2010). Isolation of Staphylococci from Food Handlers and Investigation of Their Enterotoxigenicity and Susceptibility to Some Antibiotics. J. Faculty vet. Med., University of kafkas. 16: S1-S5.

12. Singh, P. and Prakash, A. (2008). Isolation of Escherichia coli, Staphylococcus aureus and Listeria monocytogenes from milk products sold under market conditions at Agra
Region. Acta Agri. Slov., 92(1): 83-88.

13. Bauer, A.W., Kirby, W.M.M., Sherris, J.C. and Turck,M. (1966). Antibiotic susceptibility testing by a standardized single disk method. Amer. J. Clin. Pathol., 45: 493-496.

14. Holm, C. and Jespersen, L. (2003). A flow-cytometric GramStainung technique for milk associated bacteria. Appl. and Environ. Microbiol., 69: 2857-2863.

15. Vasavada, P.C. (1988). Pathogenic bacteria in milk-A review. J. Dairy Sci., 71: 2809-2816.

16. Bonfoh, B., Wasem, A., Traore, A.N., Fane, A., Spillmann, H.,Simbe, C.F., Alfaroukh, I.O., Nicolet, J., Farah, Z. and Zinsstag, J. (2003). Microbiological quality of cow's milk taken at different intervals from the udder to the selling point in Bamako (Mali). Food Control, 14: 495-500.

17. Altekruse, S., Hyman, F., Klontz, K., Timbo, B. and Tollefson, L. (1994). Food borne bacterial infections in individuals with the human immunodeficiency virus. South Med. J., 87: 69-73.

18. Fagundes, H., Barchesi, L., Filho, A.N., Ferreira, L.M. and Oliveira, C.A.F. (2010). Occurrence of Staphylococcus aureus in raw milk produced in dairy farms in São Paulo State, Brazil. Braz. J. Microbiol., 41:376-380.

19. Shah, N.M., Kher, H.N., Dholakia, P.M. and Simaria, M.B. (1985). Studies on Staphylococci in udder of cattle. Indian Vet. J., 62: 458-460.

20. Kumar, R. and Prasad, A. (2010). Detection of E.coli and Staphylococcus in Milk and Milk Products in and around Pantnagar. Vet. World., 3(11): 495-496.

21. Tambekar, D.H. and Bhutda, S.A. (2010). Prevalence of Bacteriological pathogens in Pedha (a milk product) sold in Amrawati (India). Int. J. Dairy Sci., 5(3): 173-176.

22. Ekici, K., Bozkurt, H. and Isleyici, O. (2004). Isolation of Some Pathogens from Raw Milk of Different Milch Animals. PakJ. Nutri., 3(3): 161-162.

23. Santana, E.H.W., Cunha, M.L.R.S., Oliveira, T.C.R.M., Moraes, L.B. and Alegro, L.C.A. (2010). Assessment of the risk of raw milk consumption related to staphylococcal food poisoing. Ciência Animal Brasileira., 11: 643-652.

24. Zakary, E.M., Nassif, M.Z. and Mohammed, G.M.O. (2011). Detection of Staphylococcus aureus in Bovine Milk and its Product by Real Time PCR Assay. Global J. Biotech. \& Biochem., 6(4): 171-177.

25. Lingathurai, S. and Vellathurai, P. (2011). Bacteriological quality and safety of raw cow milk in Madurai, South India. Webmed Cent. Microbiol., 1: 1-10.

26. Normanno, G., La Salandra, G., Dambrosio, A., Quaglia, N.C., Corrente, M., Parisi, A., Santagada, G., Firinu, A., Crisetti, E. and Celano, G.V. (2007). Occurrence, characterization and antimicrobial resistance of enterotoxigenic Staphylococcus aureus isolated from meat and dairy products. Int. J. Food Microbiol., 115: 290-296.

27. Addis, M., Pal, M. and Kyule, N. (2011). Isolation and Identification of Staphylococcus species from Raw Bovine Milk in Debre Zeit, Ethiopia. Vet. Res., 4(2): 45-49. 